\title{
A Novel Epitope of Entactin Is Present at the Mammalian Neuromuscular Junction
}

\author{
Arlene Y. Chiu and Jan Ko \\ Division of Neurosciences, Beckman Research Institute of the City of Hope, Duarte, California 91010
}

The extracellular matrix (ECM) at the neuromuscular junction (NMJ) is biochemically and functionally specialized, and bears molecules that can regulate both the formation and function of this peripheral synapse. We have previously purified one synaptic component of the muscle $\mathrm{ECM}-\mathrm{a}$ unique laminin isoform named s-laminin-from a rat schwannoma cell line (Chiu et al., 1992). To develop new probes for the ECM, monoclonal antibodies were generated against other components produced by this cell line. One of these new antibodies, $9 \mathrm{H} 6$, binds selectively at the synaptic cleft of NMJs in adult rats, but not at extrasynaptic sites on the muscle surface. On Western blots, 9H6 recognizes a 150 kDa band that colocalizes, and copurifies with the lamininbinding, ECM glycoprotein entactin under both reducing and nonreducing conditions. $\mathbf{N}$-terminal sequence analysis also indicates that the $9 \mathrm{H} 6$ antigen is related to entactin. However, polyclonal antibodies to entactin stain both synaptic and extrasynaptic sites. Thus, $9 \mathrm{H} 6$ appears to identify an entactin epitope with a very restricted distribution. Treatment with $\mathrm{N}$-glycanase reduces the molecular mass of entactin and eliminates $9 \mathrm{H} 6$ binding, suggesting that the $9 \mathrm{H} 6$ epitope at synapses is dependent on glycosylation. Recent studies have shown that novel isoforms of laminin, collagen IV, agrin, and AChE are selectively sequestered at the NMJ. Our results indicate that the entactin present at the synaptic cleft also differs from entactin present outside the synapse. The synaptic form of entactin may contribute to the unique functions of the ECM at the neuromuscular synapse.

[Key words: extracellular matrix, entactin, s-laminin, basement membrane, neuromuscular junction, synapse specificity, carbohydrate epitope]

It has been known since the turn of the century that when motor neurons are injured, their axons return with great fidelity to reinnervate muscles at the original synaptic sites (Tello, 1907). It follows from these observations that physical constraints and environmental cucs must guide the returning axons to the ap-

\footnotetext{
Received Aug. 23, 1993; revised Oct. 15, 1993; accepted Oct. 26, 1993.

We thank M. Ugozzoli for participation in some of the initial studies, and $E$ Engvall for the generous gift of polyclonal antibodies to human merosin. This project benefitted greatly from discussions with M.-J. Fan, Z. Kapreilian, K. Meiri, N. Ratner, and R. Wetts, and was supported by a grant from the National Science Foundation (A.Y.C.).

Correspondence should be addressed to Arlene Y. Chiu, Division of Neurosciences, Beckman Research Institute of the City of Hope, 1450 East Duarte Road, Duarte, CA 91010.
}

Copyright (C) 1994 Society for Neuroscience $0270-6474 / 94 / 142809-09 \$ 05.00 / 0$ propriate locations and promote the formation of new synapses. However, the molecules and mechanisms that regulate this process are just beginning to be understood. A major advance was the finding that extracellular molecules in the basement membrane at the neuromuscular junction (NMJ) can pinpoint sites where synaptic regeneration takes place (Sanes et al., 1978; Burden et al., 1979; Glicksman and Sanes, 1983; McMahan and Slater, 1984). These results prompted efforts to identify the relevant molecules, and study the processes by which such molecules can locally direct synapse formation.

A first step toward understanding the role of the extracellular matrix (ECM) in regulating synaptogenesis is to identify molecules unique to this region of the muscle basement membrane. Immunohistochemical studies (Sanes and Hall, 1979; Anderson and Fambrough, 1983; Sanes and Chiu, 1983), as well as studies with lectins (Sanes and Cheney, 1982; Ko, 1987; Ribera et al., 1987; Scott et al., 1988), demonstrate that synaptic ECM clearly differs biochemically from the ECM at extrasynaptic sites (reviewed in Sanes, 1989; Hall and Sanes, 1993). Moreover, a number of ECM molecules that have been implicated in the function and differentiation of the vertebrate NMJ are strategically located at the synaptic cleft. For example, the synaptic form of AChE is anchored to the basement membrane by a collagenous tail (Hall and Kelly, 1971; Hall, 1973; McMahan et al., 1978; Brandan et al., 1985; Krejci et al., 1991), where its activity is critical for normal and efficient synaptic function. A second example is agrin, a molecule released by motor neurons, that can induce focal accumulations of ACh receptors, and other postsynaptic specializations (Reist et al., 1992; reviewed in Nastuk and Fallon, 1993). Many forms of AChE and agrin are now known to exist; however, specialized, synaptic isoforms of these molecules are restricted to the synaptic cleft. A third ECM molecule that is preferentially sequestered within the synaptic cleft is the s-laminin chain, a homolog of the B1 laminin chain (Hunter et al., 1987, 1989a). In addition, antibodies specific for the A chain of laminin, and for certain subunits of collagen IV, also appear to bind selectively to the mammalian NMJ (Sanes et al., 1990). While the functions of these individual molecules are currently unknown, a larger picture of the organization of the ECM is beginning to emerge. Similar families of molecules make up the ECM at synaptic and extrasynaptic sites; however, the isoforms that are specifically expressed at the synaptic cleft differ from their homologs expressed over the rest of the muscle fiber surface. These synaptic isoforms, which may be unique polypeptides, or may have been altered by posttranslational modifications, are responsible for the distinct composition and function of the ECM at the NMJ. A new member of this group of 
Normal
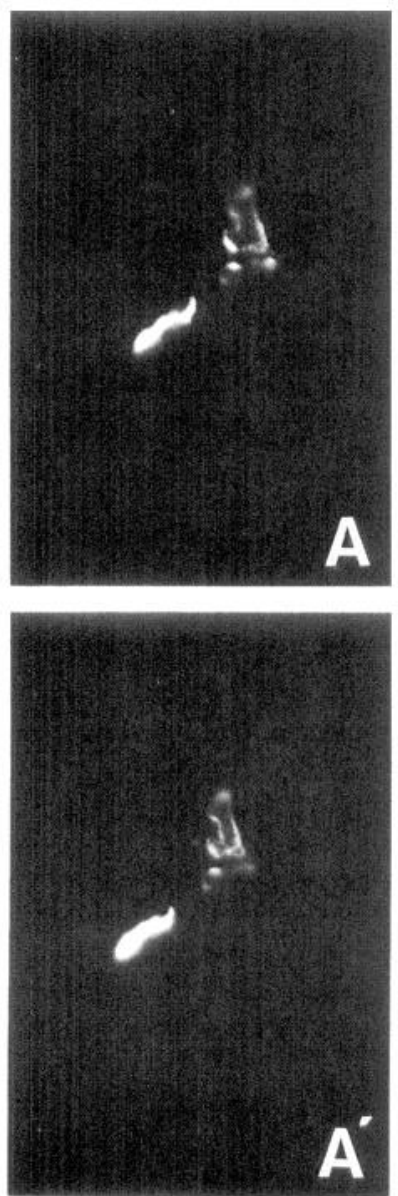

Damaged
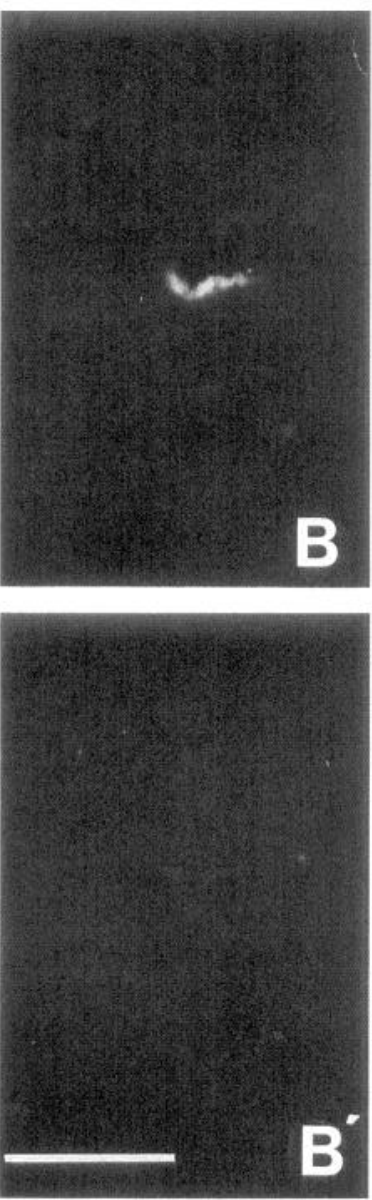

Figure 1. Monoclonal antibody $9 \mathrm{H} 6$ specifically recognizes the ECM at NMJs. Flash-frozen sections of rat muscle were reacted with $9 \mathrm{H} 6$, followed by a fluoresceinated secondary antibody to visualize sites of binding. The sections were concomitantly labeled with rhodamine- $\alpha$ bungarotoxin to identify end-plates. In normal muscles, antibody binding $(A)$ coincided with toxin binding $(A)$. Following denervation and damage to the muscle, antibody binding remained with the ECM sheaths $(B)$; however, no toxin-binding sites were left in the damaged muscles (B). Scale bar, $50 \mu \mathrm{m}$.

synapse-specific ECM molecules is the laminin-binding glycoprotein entactin. In this article, we describe a novel epitope that distinguishes entactin at the rat NMJ.

\section{Materials and Methods}

Reagents. Serum-free medium was conditioned for 3-4 d by confluent cultures of the rat schwannoma, D6P2T, as previously described (Chiu et al., 1992); $1200 \mathrm{ml}$ of conditioned medium was applied to a $70 \mathrm{ml}$ bed of DEAE-Sephacel, and eluted with a $260 \mathrm{ml}$ gradient of $10 \mathrm{~mm}$ to $1.2 \mathrm{M} \mathrm{NaCl}$ in $10 \mathrm{~mm}$ imidazole, $\mathrm{pH} \mathrm{7.0.} \mathrm{Fractions} \mathrm{of} 0.6 \mathrm{ml}$ each were collected and analyzed for the presence of different ECM components by Western blots. Fractions with a high entactin content were pooled and concentrated fivefold in a Savant Speedvac concentrator before applying onto a $50 \mathrm{ml}$ bed of $400 \mathrm{HR}$-Sephacryl, equilibrated in $10 \mathrm{~mm}$ imidazole, $\mathrm{pH} 7.0$, with $10 \mathrm{~mm} \mathrm{NaCl}$. The first peak of protein was pooled and used for Western blot analyses or subjected to further purification by electrophoresis on low-melting-point agarose gels, as previously described (Chiu et al., 1992; Ugozzoli and Chiu, 1992).

Generation of monoclonal antibody 9H6. Schwannoma ECM components were purified and extracted from slices of agarose following electrophoresis; material that migrated with an apparent molecular mass of $185-140 \mathrm{kDa}$ were pooled and injected into $\mathrm{Balb} / \mathrm{c}$ mice to generate

\section{A. Without reduction}

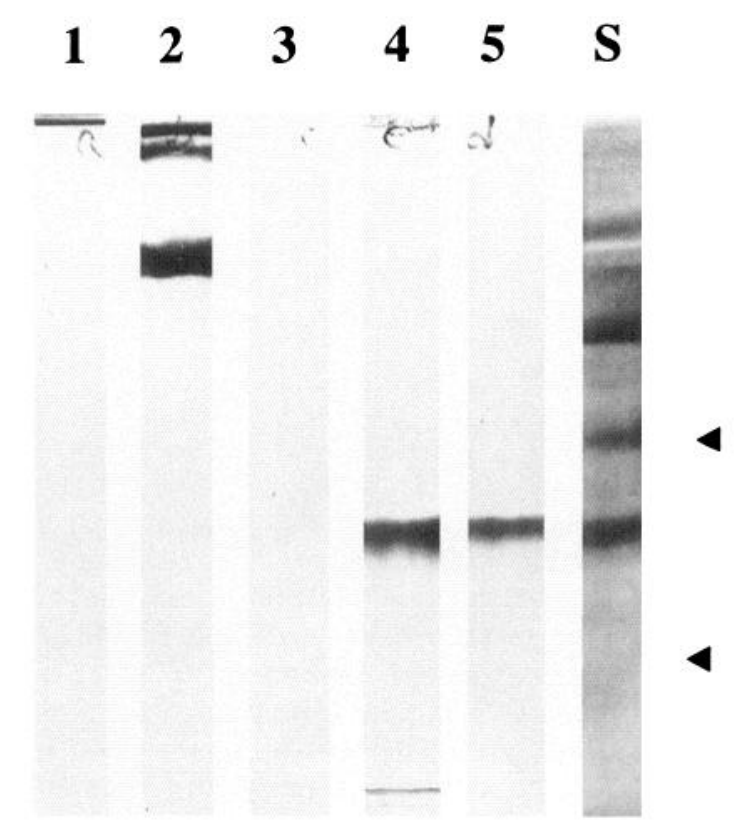

B. With reduction

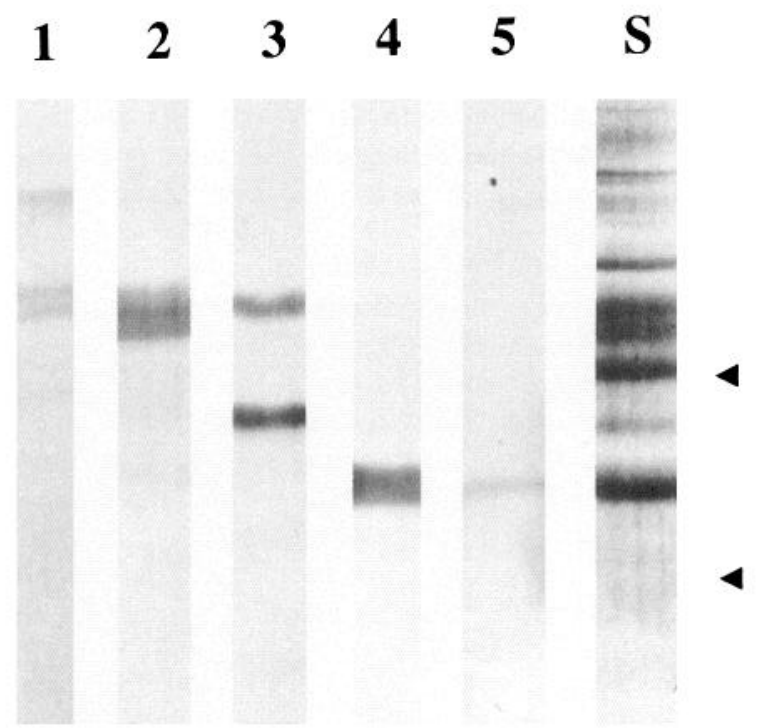

Figure 2. $9 \mathrm{H} 6$ recognizes a band that colocalizes with entactin on Western blots. Preparations of schwannoma ECM were separated by SDS-PAGE in the absence $(A)$ and presence $(B)$ of reduction, transferred onto nitrocellulose, and incubated with different antibodies to identify individual ECM components. The presence of tenascin (lane 1) and the $\mathrm{B}$ chains of laminin (lane 2) was observed with polyclonal antibodies. Monoclonal antibody C4 bound to both the B1 chain $(205 \mathrm{kDa})$ and $\mathrm{s}$-laminin $(185 \mathrm{kDa})$ following reduction (lane 3$)$. Polyclonal antibodies to entactin (lane 4) bound a band at 140-150 kDa that was also seen using monoclonal antibody 9H6 (lane 5). Silver staining revealed the protein content of each gel (lane $S$ ). The arrowheads indicate the relative migrations of molecular weight markers myosin $(200 \mathrm{kDa})$ and phosphorylase b $(92.5 \mathrm{kDa})$. 


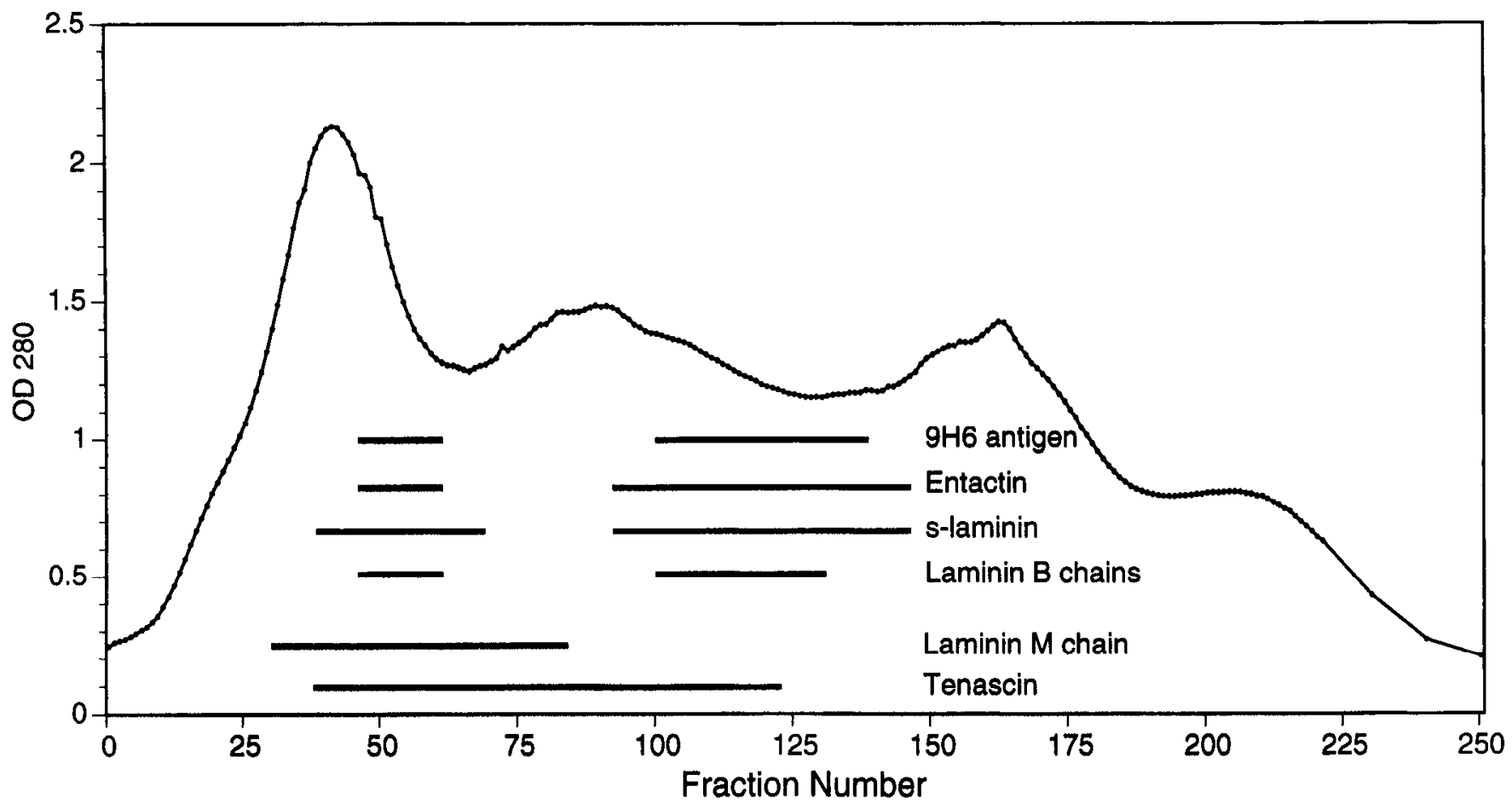

Figure 3. The $9 \mathrm{H} 6$ antigen copurifies with entactin. Over a liter of medium conditioned by the rat schwannoma D6P2T was separated by ion exchange chromatography and eluted with a gradient of $\mathrm{NaCl}$. Bars indicate fractions bearing the highest concentrations of individual matrix components, as determined from Western blots.

monoclonal antibodies. Hybridoma supernatants were screened on sections of rat muscles, as previously described (Sanes and Chiu, 1983); end-plates were identified with rhodamine-labeled $\alpha$-bungarotoxin. Hybridomas were subcloned if their antibodies bound selectively at endplates.

Immunohistochemistry. Sections $6 \mu \mathrm{m}$ thick of flash-frozen rat muscles and kidneys were cut on a Reichardt-Jung Frigo-Cut cryostat, picked up on alcohol-cleaned slides, and stored at $-20^{\circ} \mathrm{C}$ till used. The following primary antibodies were used: $9 \mathrm{H} 6$ hybridoma supernatant, applied without dilution; ascites of monoclonal antibody $\mathrm{C1}$, diluted $1: 1000$ with phosphate-buffered saline containing $0.05 \%$ Tween 20 (PBS-Tween); rabbit anti-entactin (UBI, Lake Placid, NY) at 1:2500 dilution with PBS-Tween. After overnight incubation at room temperature in primary antibodies, sections were rinsed thrice in PBS-Tween before a $1 \mathrm{hr}$ incubation in a mixture of the appropriate fluoresceinated secondary antibodies (1:100 dilution) and rhodamine-labeled $\alpha$-bungarotoxin (1: 3000 dilution; Molecular Probes, Eugene, OR). Goat anti-mouse IgM (Chemicon, Temecula, CA) was used to visualize 9H6 binding; goat anti-mouse IgG (Chemicon) for $\mathrm{Cl}$, and goat anti-rabbit IgG (Chemicon) for anti-entactin. The diluting buffer, PBS-Tween, was supplemented with $2 \%$ normal goat serum to reduce nonspecific binding. After rinsing off excess secondary antibodies, sections were examined under an Olympus IMT-2 fluorescence microscope equipped with separate filters for viewing fluorescein and rhodamine independently.

Polyacrylamide gel electrophoresis (PAGE) and Western blots. Sodium dodecyl sulfate (SDS) gel electrophoresis was performed in $5.5 \% \mathrm{~min}$ igels, according to the method of Laemmli (1970). Transfer of gelresolved proteins onto nitrocellulose was conducted as previously described (Chiu et al., 1991). Each blot was preincubated for $30 \mathrm{~min}$ in PBS containing $1 \%$ bovine serum albumin to block nonspecific binding prior to overnight incubation with primary antibodies at room temperature. Commercial polyclonal antibodies were used to identify tenascin (Chemicon), laminin (Chemicon), and entactin (UBI). Rabbit antihuman merosin was generously provided by Dr. E. Engvall (La Jolla Cancer Research Foundation, La Jolla, CA) and used to identify the rat $M$ chain of laminin. All polyclonal antibodies were diluted with PBSTween. Hybridoma supernatant of $9 \mathrm{H} 6$, and of the monoclonal antibody C4, which recognizes s-laminin in situ (Sanes and Chiu, 1983), was used undiluted on Western blots, as previously described (Chiu et al., 1991). Following a $1 \mathrm{hr}$ incubation in the appropriate secondary antibody, conjugated to horseradish peroxidase and diluted 1:1000 with PBS-Tween, sites of binding were visualized with 4-chloronaphthol.

$N$-terminal sequence analysis. Approximately $250 \mu \mathrm{g}$ of protein from schwannoma-conditioned medium, purified by ion exchange chromatography, gel filtration, and electrophoresis on agarose gels, was further separated by SDS-PAGE and transferred onto Immobilon polyvinylidene difluoride membrane (Millipore Corp., Bedford, MA). Adjacent lanes were reacted with $9 \mathrm{H} 6$ to identify the antigen; the immunoreactive band, visualized by Coomassie staining, was cut out and subjected to automated Edman degradation, using a sequenator built at the City of Hope (Hawke et al., 1985). phenylthiohydantoin-amino acids were detected by on-line HPLC systems.

Digestion with $\mathrm{N}$-glycanase. For partial digestion with $\mathrm{N}$-glycanase (Genzyme, Cambridge, MA), a sample containing $17 \mu \mathrm{g}$ of schwannoma ECM, partially purified by ion exchange and gel filtration chromatography, was incubated in the presence of $0.65 \mathrm{U}$ of recombinant $\mathrm{N}$-glycanase overnight at $37^{\circ} \mathrm{C}$ prior to Western blot analysis (i.e., $23 \mu \mathrm{g} / \mathrm{U}$ enzyme). For more complete deglycosylation, $0.75 \mathrm{U}$ of enzyme was used to digest $14 \mu \mathrm{g}$ of sample (18.6 $\mu \mathrm{g} / \mathrm{U}$ enzyme). In each case, the control sample was incubated without enzyme. To test the effect of deglycosylation on $9 \mathrm{H} 6$ immunoreactivity at NMJs, cryostat sections of rat muscles werc incubated overnight at $37^{\circ} \mathrm{C}$ with $\mathrm{N}$-glycanase $(64$ $\mathrm{U} / \mathrm{ml} \mathrm{PBS}$ ) in a humidified chamber, then rinsed thrice in PBS before immunohistochemistry.

\section{Results}

Monoclonal antibody 9116 recognizes an ECM component at the NMJ

To obtain new probes to ECM components, monoclonal antibodies were generated against matrix molecules partially purified from medium conditioned by the rat schwannoma D6P2T. Fresh-frozen sections of adult rat diaphragm were used in screening for antibodies that recognized synaptic components. One such monoclonal antibody, 9H6, selectively stained sites that were identified as end-plates by concurrent $\alpha$-bungarotoxin binding (Fig. 1 $A, A$ ). Since pre- and postsynaptic membranes, as well as the intervening ECM, are normally closely opposed 


\section{Anti-entactin}
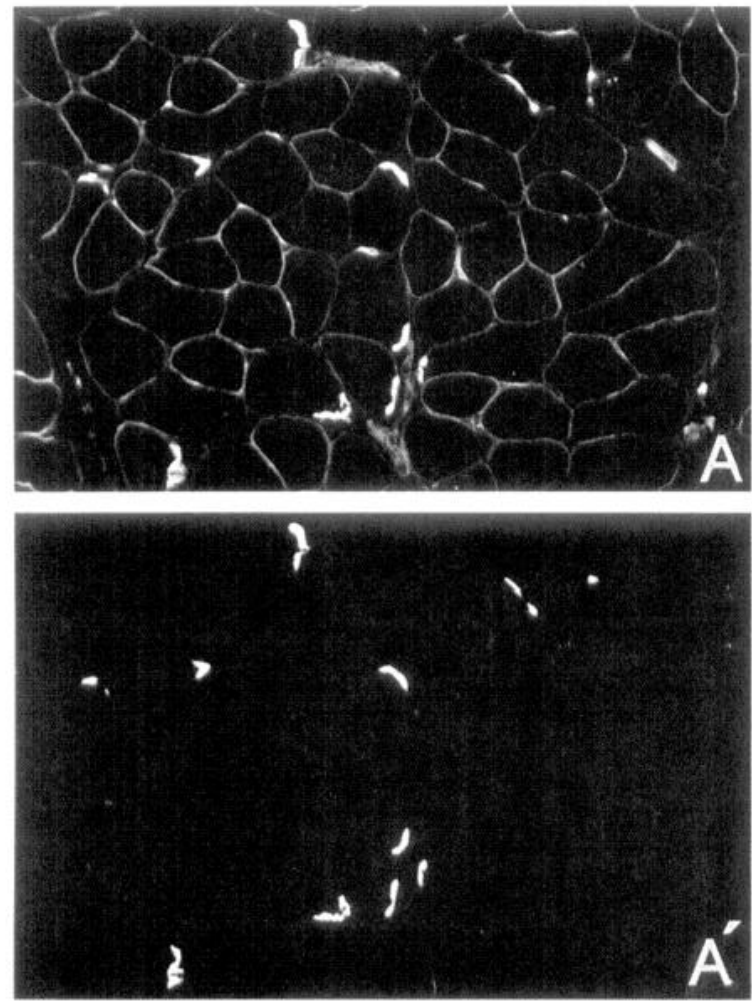

9 H6
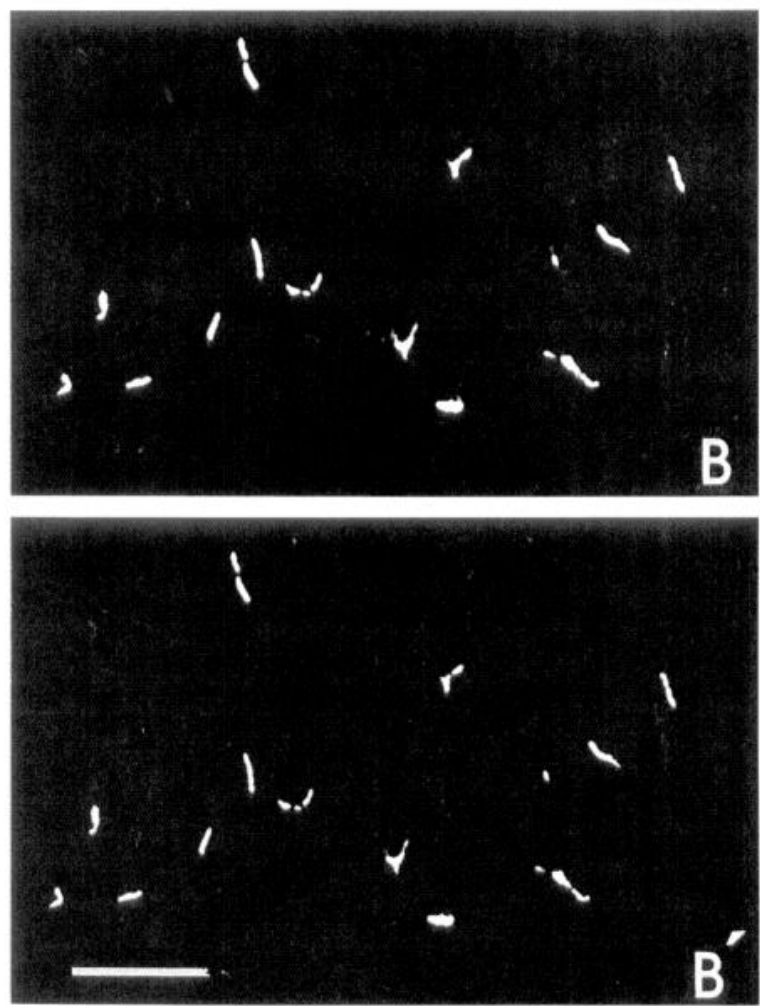

Figure 4. Comparison of $9 \mathrm{H} 6$ and anti-entactin immunoreactivity in rat muscle. The distribution of entactin $(A)$ was viewed, using polyclonal antibodies, and compared with sites of $9 \mathrm{H} 6$ binding $(B)$ in neighboring sections of rat muscle. Both types of antibodies stained synapses, as identified by rhodamine-labeled $\alpha$-bungarotoxin in the same fields $\left(A^{\prime}\right.$ and $\left.B\right)$. However, anti-entactin also bound to extrasynaptic surfaces of muscle fibers. Scale bar, $200 \mu \mathrm{m}$.

at the $\mathrm{NMJ}$, we needed a different preparation to determine where the immunoreactive epitope resided at this synapse. To resolve this issue, the sternomastoid muscle was denervated and damaged to eliminate both pre- and postsynaptic cells, leaving behind the "ghosts" of ECM sheaths (Sanes and Hall, 1979). In

Table 1. Tissue distribution of immunoreactivity for laminin and entactin

\begin{tabular}{lllll} 
& $\begin{array}{l}\text { Poly- } \\
\text { clonal } \\
\text { anti- } \\
\text { laminin }\end{array}$ & $\begin{array}{l}\text { Mono- } \\
\text { clonal } \\
\text { anti- } \\
\text { body }\end{array}$ & $\begin{array}{l}\text { Poly- } \\
\text { clonal } \\
\text { anti- } \\
\text { entac- } \\
\text { tin }\end{array}$ & $\begin{array}{l}\text { Mono- } \\
\text { clonal } \\
\text { anti- } \\
\text { body } \\
9 \mathrm{H} 6\end{array}$ \\
\hline $\begin{array}{lllll}\text { Muscle } \\
\text { Neuromuscular junctions }\end{array}$ & +++ & +++ & +++ & +++ \\
Myotendinous junctions & +++ & +++ & +++ & +++ \\
Extrajunctional sites & ++ & - & ++ & - \\
Intrafusal fibers & +++ & +++ & ++ & +++ \\
Spindle capsule & +++ & +++ & ++ & - \\
Peripheral nerves & & & & \\
Perineurium & +++ & +++ & ++ & - \\
Endoneurium & ++ & + & ++ & + \\
Kidney & & & & \\
$\quad \begin{array}{llll}\text { Glomeruli } \\
\text { Tubules }\end{array}$ & +++ & +++ & ++ & - \\
Blood vessels & +++ & - & ++ & - \\
\hline
\end{tabular}

sections of muscles damaged in this manner, the absence of $\alpha$-bungarotoxin binding (Fig. $1 B^{\prime}$ ) confirmed the loss of muscle membranes. In these preparations, immunoreactivity for $9 \mathrm{H} 6$ persisted at the original synaptic sites (Fig. $1 B$ ), indicating that the epitope is located in the basement membrane at the synaptic cleft.

\section{Identification of the $9 H 6$ antigen}

Western blot analyses were employed to identify the antigen recognized by $9 \mathrm{H} 6$. Preparations of the original immunogen used to generate this antibody were separated by electrophoresis in the presence (Fig. $2 B$ ) or absence (Fig. $2 A$ ) of reducing agents, transferred onto nitrocellulose, and reacted with $9 \mathrm{H} 6$, as well as with a number of antibodies specific for known ECM molecules. Binding by $9 \mathrm{H} 6$ revealed a single, $150 \mathrm{kDa}$ band that coincided with a band recognized by anti-entactin antibodies when electrophoresis took place without reduction (Fig. $2 A$, lanes 4,5$)$. This colocalization persisted in the presence of reducing agents (Fig. $2 B$, lanes 4,5 ); however, $9 \mathrm{H} 6$ binding was diminished under these conditions. No binding by $9 \mathrm{H} 6$ was seen at bands identified by anti-tenascin (lane 1), anti-laminin (lane 2), or C4 (lane 3), a monoclonal antibody that reacts with both the s-laminin and the B1 laminin chains, on Western blots (Hunter et al., 1987, 1989a; Chiu et al., 1991, 1992). Other, unidentified proteins in the preparation could be seen with silver stain (lane S). Thus, the $9 \mathrm{H} 6$ antigen colocalized only with the entactin on Western blots. 
This $150 \mathrm{kDa}, 9 \mathrm{H} 6$ antigen also copurified with entactin when schwannoma-conditioned medium was separated by ion exchange chromatography and gel filtration. More than 1 liter of conditioned medium was applied onto DEAE-Sephacel, and eluted with a gradient of $10 \mathrm{~mm}$ to $1.2 \mathrm{M} \mathrm{NaCl}$, as previously described (Chiu et al., 1992). To determine the distribution of different ECM molecules, aliquots containing equivalent amounts of total protein from every fifth fraction were analyzed on Western blots. The $150 \mathrm{kDa}, 9 \mathrm{H} 6$-immunoreactive band copurified with entactin, and was most prominent in fractions bearing the highest levels of entactin (Fig. 3). These fractions were also enriched for the smaller (185-220 kDa) laminin subunits: the $\mathrm{B} 1, \mathrm{~B} 2$, and s-laminin chains. In contrast, immunoreactivity for the larger $(300 \mathrm{kDa}), \mathrm{M}$ chain of laminin was only present in the first peak of entactin immunoreactivity, and the tenascin bands, most abundant in fractions 33-120, showed no meaningful overlap with the other ECM components examined. Entactin-enriched fractions were then separated by gel filtration chromatography. The $9 \mathrm{H} 6$ antigen and the entactin band eluted with an apparent molecular mass of greater than 1 million Da; again, both were found in the same fractions (data not shown).

When the purified $150 \mathrm{kDa}, 9 \mathrm{H} 6$-immunoreactive band was subjected to Edman degradation, a single $\mathrm{N}$-terminal sequence of 18 amino acids was obtained: $\mathrm{NH}_{3}$-leu-asn-arg-gln-glu-leuphe-pro-phe-gly-pro-gly-gln-X-asp-leu-glu-leu. This is an exact match of the N-terminal sequence of mouse entactin (Durkin et al., 1988), assuming a glycine is present at the X position.

If monoclonal antibody $9 \mathrm{H} 6$ recognized an epitope present on entactin, we reasoned that polyclonal antibodies to entactin should bind to histological sites identified by $9 \mathrm{H} 6$. In sections of rat muscle, anti-entactin stained both synaptic and extrasynaptic surfaces (Fig. 4A), although immunoreactivity was enhanced at end-plates. In contrast, $9 \mathrm{H} 6$ only bound to the ECM at the NMJ (Fig. $4 B$ ). In a survey of ECM from other tissues, entactin-like immunoreactivity was present at, but not restricted to, all sites where $9 \mathrm{H} 6$ bound (Table 1). Thus, polyclonal antibodies to entactin revealed a distribution that completely overlapped with, but was much more extensive than that seen with the monoclonal antibody $9 \mathrm{H} 6$.

\section{The $9 H 6$ epitope is destroyed by $\mathrm{N}$-glycanase}

In order to characterize the epitope recognized by $9 \mathrm{H} 6$, schwannoma ECM was digested with $\mathrm{N}$-glycanase prior to Western blot analysis. With deglycosylation, entactin migrated to a lower position during electrophoresis (Fig. 5). At low enzyme concentrations, only some of the molecules were deglycosylated, and two bands were revealed with anti-entactin (Fig. 5A, lane 2). When sufficient enzyme was used, the $150 \mathrm{kDa}$ band was lost, with a concomitant rise in the lower band, indicating that the lower band consisted of deglycosylated entactin (Fig. $5 B$, lane 2). Sister blots, reacted with $9 \mathrm{H} 6$, showed a reduction in the $150 \mathrm{kDa} 9 \mathrm{H} 6$-immunoreactive band at low enzyme concentrations (Fig. $5 A$, lane 4 ). When $\mathrm{N}$-glycanase concentration was increased, no immunoreactivity could be seen with 9H6 (Fig. $5 B$, lane 4$)$. The deglycosylated form of entactin, identified by polyclonal antibodies, was not recognized by $9 \mathrm{H} 6$. The binding of $9 \mathrm{H} 6$ at end-plates was also vulnerable to deglycosylation (Fig. 6). Synaptic immunoreactivity was lost when sections of rat muscle were incubated in the presence of $\mathrm{N}$-glycanase prior to immunohistochemistry. Thus, binding by $9 \mathrm{H} 6$, both on Western blots and in tissue, must require N-linked glycosylation of entactin.

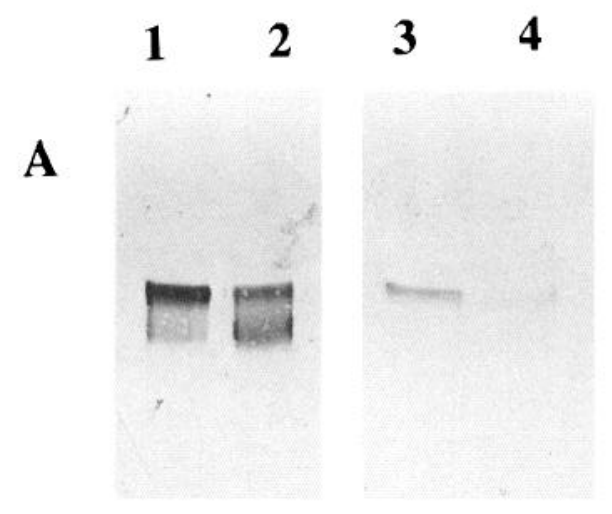

\section{B}
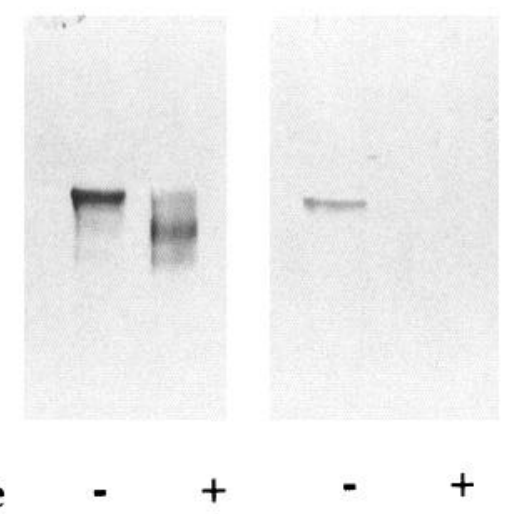

\section{N-glycanase}

Figure 5. N-glycanase digestion reduces the molecular mass of entactin, and eliminates $9 \mathrm{H} 6$ immunoreactivity on Western blots. An entactin-enriched preparation of schwannoma ECM was partially digested $(A)$, at $23 \mu \mathrm{g}$ protein/U N-glycanase, and more completely deglycosylated $(B)$ at $18.6 \mu \mathrm{g}$ protein/U enzyme. Control samples (lanes $I$ and 3 ) were incubated in the absence of enzyme. Polyclonal anti-entactin antibodies (lanes $I$ and 2 ) revealed that entactin migrated farther following removal of $\mathrm{N}$-linked carbohydrates; the lower band increasing in intensity with increasing enzyme activity. The 9H6-immunoreactive band, which comigrates with entactin in the absence of enzyme (lane 3), is lost upon deglycosylation (lane 4).

\section{Distribution of 9 H6 immunoreactivity is much more restricted than that for s-laminin}

Since the immunogen preparation that was used to generate 9H6 contained s-laminin, we sought to determine if the $9 \mathrm{H} 6$ epitope is present on s-laminin. However, the $150 \mathrm{kDa}$ band recognized by $9 \mathrm{H} 6$ did not comigrate with s-laminin, which has a molecular mass of $185 \mathrm{kDa}$ (Fig. $2 \mathrm{~B}$, lane 3 ). We also compared the distribution of s-laminin immunoreactivity with sites of binding by $9 \mathrm{H} 6$ in muscle ECM, as well as ECM from other tissues. Consecutive sections were stained with $9 \mathrm{H} 6$, and with a second monoclonal antibody, $\mathrm{Cl}$, which specifically recognizes s-laminin-rich sites (Sanes and Chiu, 1983; Chiu and Sanes, 1984). Both antibodies selectively stained end-plates (Fig. 7 $A, A$ ), myotendinous junctions (Fig. $7 B, B$ ), and intrafusal muscle fibers (Fig. $7 C, C^{\prime}$ ) in adult rat muscles. However, binding by $9 \mathrm{H} 6$ was conspicuously absent at a number of sites bearing high levels of s-laminin, including the muscle spindle sheath (Fig. $7 C$ ), the perineurium surrounding peripheral nerves (Fig. 7D), walls of blood vessels (Fig. $7 E^{\prime}$, and arrows in Fig. $7 C^{\prime}-E^{\prime}$ ), as well as in kidney glomeruli (Fig. $7 F^{\prime}$ ). Thus, the two patterns of immunoreactivity overlapped only on muscle ECM; the $9 \mathrm{H} 6 \mathrm{ep}-$ itope appears to have a more limited distribution than that seen for s-laminin (Table 1). 


\section{With N-glycanase}
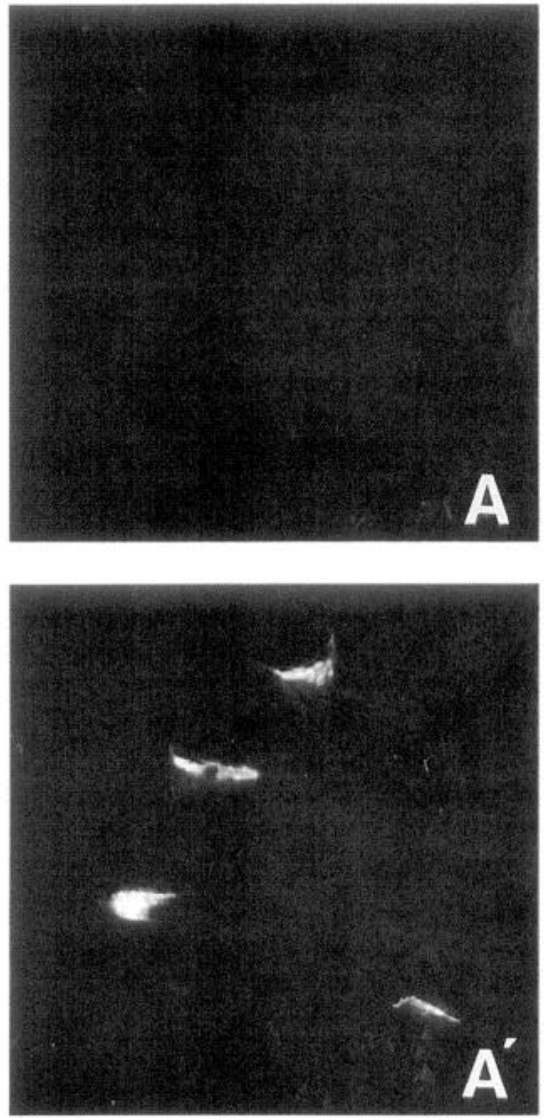

Without N-glycanase
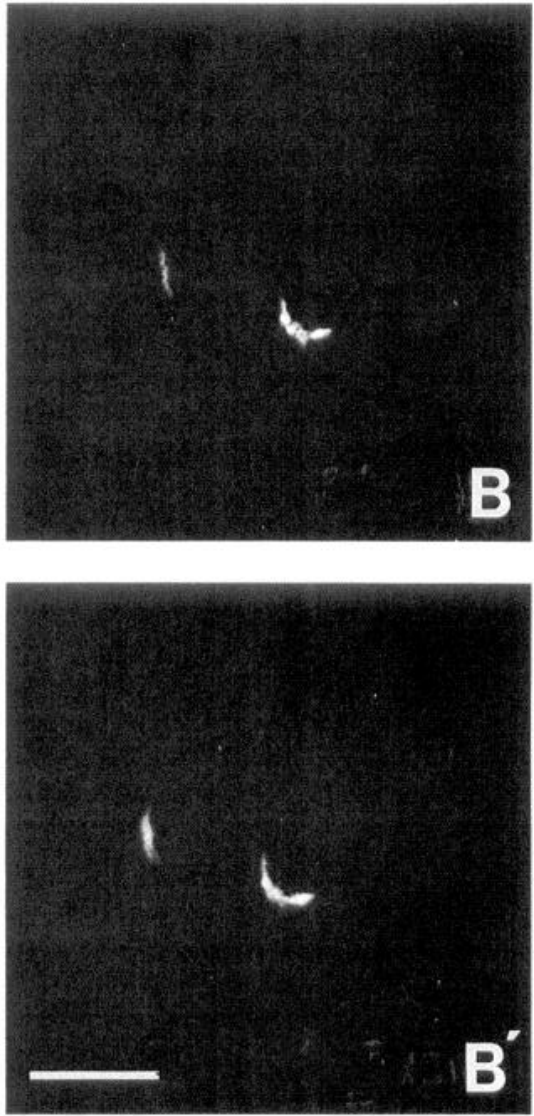

Figure 6. N-glycanase eliminated immunoreactivity for $9 \mathrm{H} 6$ at NMJs. Cryostat sections of fresh frozen rat muscles were maintained at $37^{\circ} \mathrm{C}$ in the presence $(A)$ or absence $(B)$ of $\mathrm{N}$-glycanase, prior to incubation with monoclonal antibody $9 \mathrm{H} 6$, and fluoresceinated secondary antibodies. End-plates were identified in the same field with rhodamine- $\alpha$-bungarotoxin $\left(A^{\prime}\right.$ and $\left.B\right)$. Immunoreactivity for $9 \mathrm{H} 6$ was lost following deglycosylation $(A)$. Scale bar, $100 \mu \mathrm{m}$.

\section{Discussion}

Since the ECM at the original site of the NMJ can direct synaptic regeneration (Sanes et al., 1978; Burden et al., 1979; Glicksman and Sanes, 1983; McMahan and Slater, 1984; Goldman et al., 1991; Brenner et al., 1992; Jo and Burden, 1992), considerable attention has been paid to identifying unique molecules localized to this region of the muscle ECM sheath. We have presented evidence that a novel epitope of entactin, recognized by a monoclonal antibody, 9H6, is highly concentrated or especially accessible at the rat NMJ. On Western blots, $9 \mathrm{H} 6$ binds to a single band of $150 \mathrm{kDa}$ that comigrates with entactin, under both reducing and nonreducing conditions. This 9H6-immunoreactive antigen also copurifies with entactin. $\mathrm{N}$-terminal sequence analysis of this band reveals a single sequence that is an exact match of the N-terminus of rodent entactin. Finally, N-glycanase digestion resulted in the loss of the $150 \mathrm{kDa}$ band of entactin, as seen with polyclonal antibodies, and a concomitant elimination of $9 \mathrm{H} 6$ immunoreactivity on Western blots. The $9 \mathrm{H} 6$ epitope thus appears to be dependent on the glycosylation pattern of entactin. Since neuromuscular and myotendinous junctions are immunoreactive for $9 \mathrm{H} 6$, the entactin molecules present at these sites may differ from their extrajunctional counterparts in the carbohydrate moieties they bear. We cannot, however, rule out the alternative explanation that the $9 \mathrm{H} 6 \mathrm{ep}-$ itope is masked, and therefore unavailable for binding, at extrasynaptic sites. In either case, our results indicate that the entactin molecule differs between synaptic and extrasynaptic sites, and this difference resides in the pattern of glycosylation.
Synapse-specific carbohydrates have been described by several laboratories. Human, rabbit, rat, mouse, guinea pig, chick, frog, axolotl, snake, fish, and lamprey end-plates all bear high concentrations of a terminal $\mathrm{N}$-acetylgalactosaminyl moiety that is recognized by two lectins, Dolichos biflorus agglutinin and Vicia villosa- $B_{4}$ agglutinin (Sanes and Cheney, 1982; Ribera et al., 1987; Scott et al., 1988). These lectins bind to the asymmetric, collagen-tailed form of AChE, which is highly concentrated at synapses, but not to the more widely distributed globular forms of the enzyme (Scott et al., 1988). A lectin with a different specificity, peanut agglutinin, also binds selectively to the ECM at frog neuromuscular and myotendinous junctions (Ko, 1987, 1991), and appears to recognize a glycoconjugate of $30 \mathrm{kDa}$ (Xiao et al., 1993). We have not as yet identified the carbohydrate moiety on entactin that is responsible for $9 \mathrm{H} 6$ immunoreactivity. Future experiments will enable us to determine if any of these lectins also bind to the entactin molecules at the NMJ. However, these lectin studies independently confirm the idea that differential glycosylation can confer a special identity to ECM molecules at synaptic sites.

The distinct nature of the basement membrane at the NMJ may arise from (1) differences in the carbohydrate composition of the resident molecules, (2) the presence of synaptic isoforms that have unique primary sequences, and (3) conformational changes in tertiary structure due to interactions with other ECM components that are specialized at the synaptic cleft. The synaptic forms of entactin and AChE are examples of molecules with carbohydrate specializations at the NMJ. S-laminin is an example of the second type of specialization. While immuno- 

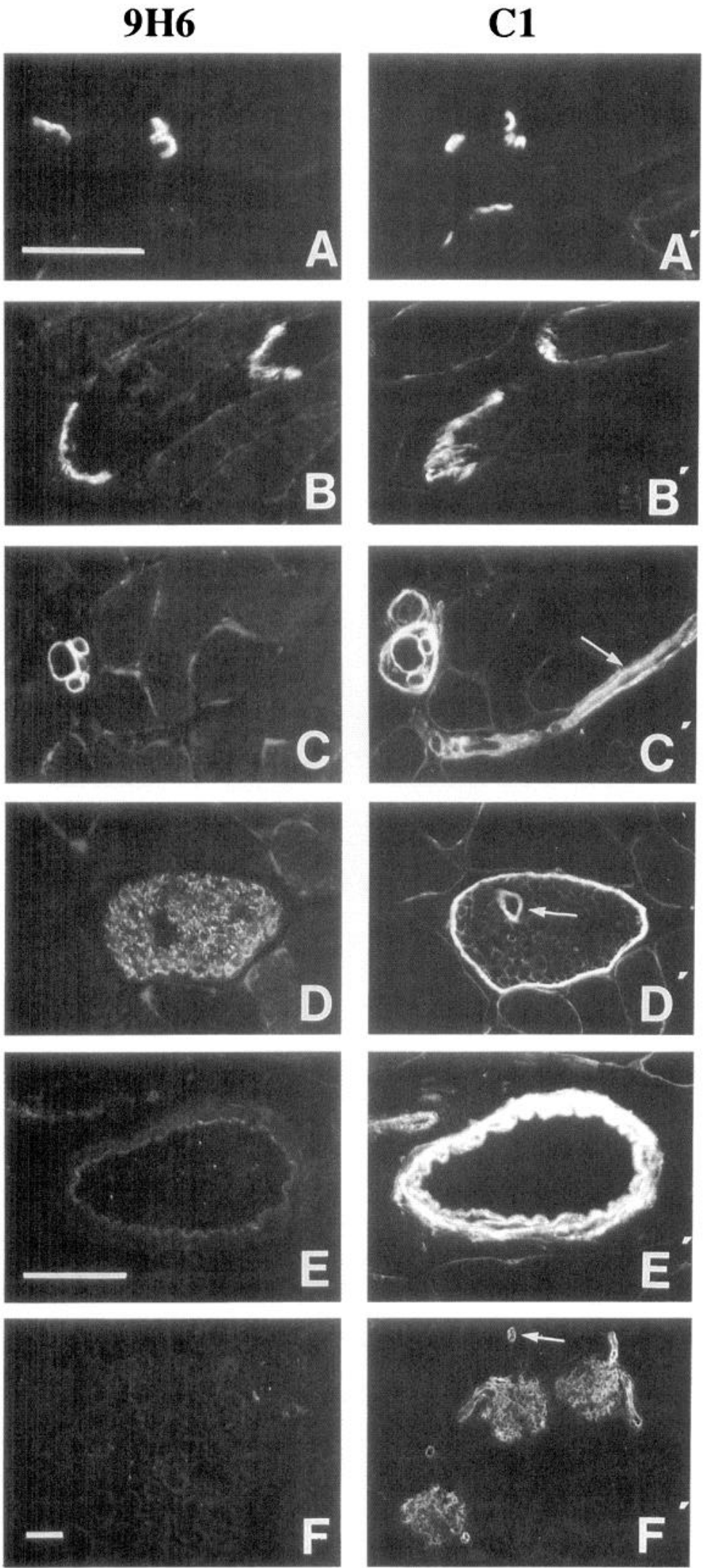

\section{Neuromuscular Junctions}

\section{Myotendinous \\ Junctions}

\section{Muscle Spindle}

\section{Peripheral Nerve}

\section{Blood Vessel}

\section{Kidney}

Figure 7. Immunoreactivity for $9 \mathrm{H} 6$ is more restricted than the distribution of s-laminin. Adjacent cryostat sections were reacted with $9 \mathrm{H} 6$ ( $A$ $F$ ), or with another monoclonal antibody, $\mathrm{Cl}$, that recognizes s-laminin $\left(A^{\prime}-F^{\prime}\right)$, and visualized with fluoresceinated secondary antibodies. Both monoclonal antibodies bound to end-plates $\left(A, A^{\prime}\right)$, myotendinous junctions $(B, B)$, and intrafusal muscle fibers $(C, C)$. Within peripheral nerves, 9H6 immunoreactivity decorated the endoneurium, on the abaxonal surfaces of Schwann cells $(D)$. However, unlike $\mathrm{Cl}$, $9 \mathrm{H} 6$ did not bind to the muscle spindle capsule $(C)$, the perineurium of peripheral nerves $(D)$, blood vessels $\left(E\right.$ and the arrows in $C^{\prime}, D^{\prime}$, and $\left.F^{\prime}\right)$, and kidney glomeruli $(F)$. Sections in $B-E$ share the same scale bar. Scale bars, $50 \mu \mathrm{m}$. 
reactivity for s-laminin is concentrated at end-plates, B1 immunoreactivity is found everywhere on the muscle fiber surface, except at synapses (Sanes and Chiu, 1983; Engvall et al., 1990). Thus, the relatively rare s-laminin subunit replaces its more abundant homolog, the B1 chain, within the synaptic cleft.

Laminin molecules are believed to be organized as heterotrimers, each consisting of one long and two short chains. Currently, two long chains (the $A$ and $M$ chains) and three short subunits (the B1, B2, and s-laminin chains) have been described. Studies using chain-specific antibodies show that the $s$ and B1 subunits can each be precipitated in the company of other laminin chains, but never together (Green et al., 1992; A. Y. Chiu, unpublished observations). These results indicate that the subunit composition of laminin at synapses must be different from laminin outside the synapse. Entactin is known to bind strongly with laminin. However, binding between the entactin molecule and the extrasynaptic, but not the synaptic, form of laminin may prevent the $9 \mathrm{H} 6$ antibody from recognizing its epitope. Thus, interaction with other ECM components could potentially alter tertiary structure, resulting in a conformational difference between synaptic and extrasynaptic molecules.

At present, a small number of matrix molecules that are selectively sequestered at the synaptic cleft have been identified, and each appears to serve a critical function at the NMJ. AChE maintains effective synaptic transmission. Agrin is likely to direct the organization of the postsynaptic apparatus on the muscle surface during development and regeneration (reviewed in McMahan et al., 1992; Nastuk and Fallon, 1993). S-laminin is preferentially adhesive to motor neurons (Hunter et al., 1989b, 1991), and may attract and keep motor axons at end-plates (Chiu and Sanes, 1984).

Entactin, also known as nidogen, is a dumbbell-shaped, sulfated glycoprotein that frequently copurifies with laminin (Timpl el al., 1983; Paulsson el al., 1987; see Fig. 3). A ubiquitous component of basement membranes, entactin displays many of the properties associated with other basement membrane proteins. For example, the preferential adhesion and migration of a number of cell types have been observed on entactin substrates in vitro, in part mediated by integrin recognition of an RGD sequence on entactin (Alstadt et al., 1987; Chakravarti et al., 1990; Senior et al., 1992; Yelian et al., 1993).

Although the function(s) of a synaptic form of entactin is currently not known, the very restricted distribution of the $9 \mathrm{H} 6$ antigen, even when compared with s-laminin (Fig. 7, Table 1), suggests a very specific function. Two possibilities present themselves. First, this molecule may prevent motor axons from sprouting beyond the end-plate, and initiate the formation and maintenance of a presynaptic terminal at this site. In support of this idea, there is evidence that the schwannoma RN22 produces a factor that inhibits neurite outgrowth on laminin substrates (Muir et al., 1989). Although the inhibitory molecule(s) has not been identified, we have found that schwannoma cell lines, such as RN22 and D6P2T, produce and release s-laminin (Chiu et al., 1991) as well as the 9H6 antigen. If ECM components, such as laminin and entactin, promote and guide neurons toward potential targets in situ, then the localized presence of specialized isoforms of these molecules may act to terminate axonal elongation and initiate synapse formation. A second possibility arises from the remarkable ability of entactin to bind and interlink laminin, collagen IV, fibronectin, heparan sulfate proteoglycans, and other components of the ECM (Dziadek et al., 1985; Aumailley et al., 1989, 1993; Mann et al., 1989; Chung and Durkin, 1990; Wu and Chung, 1991; Wu et al., 1991; Battaglia et al., 1992; Senior et al., 1992). Since these ECM components interact independently with entactin, this promotes the formation of ternary complexes between laminin, collagen IV, and proteoglycans, and suggests a key role for entactin in the assembly and stabilization of basement membranes (reviewed in Chung and Durkin, 1990; Chung et al., 1993). Interestingly, synaptic isoforms of laminin (Hunter et al., 1987, 1989a), collagen IV (Sanes et al., 1990), and heparan sulfate proteoglycan (Anderson and Fambrough, 1983) are present at vertebrate endplates. A specialized form of entactin at the NMJ may be the means by which the synaptic isoforms of many ECM molecules are selectively anchored to this critical site on the muscle surface.

\section{References}

Alstadt SP, Hebda PA, Chung AE, Eaglestein WH (1987) Effect of basement membrane entactin on epidermal cell attachment and growth. J Invest Dermatol 88:55-59.

Anderson, MJ, Fambrough DM (1983) Aggregates of acetylcholine receptors are associated with plaques of a basal lamina heparan sulfate proteoglycan on the surface of skeletal muscle fibers. J Cell Biol 97: $1396-1411$.

Aumailley M, Wiedemann H, Mann K, Timpl R (1989) Binding of nidogen and the laminin-nidogen complex to basement membrane collagen type IV. Eur J Biochem 184:241-248.

Aumailley M, Battaglia C, Mayer U, Reinhardt D, Mischt R, Timpl R, Fox JW (1993) Nidogen mediates the formation of ternary complexes of basement membrane components. Kidney Int 43:7-12.

Battaglia C, Mayer U, Aumailley M, Timpl R (1992) Basement-membrane heparan sulfate proteoglycan binds to laminin by its heparan sulfate chains and to nidogen by sites in the protein core. Eur J Biochem 208:359-366.

Brandan E, Maldonado M, Garrido J, Inestrosa NC (1985) Anchorage of collagen-tailed acetylcholinesterase to the extracellular matrix is mediated by heparan sulfate proteoglycans. J Cell Biol 101:985-992.

Brenner HR, Herczeg A, Slater CR (1992) Synapse-specific expression of acetylcholine receptor genes and their products at original synaptic sites in rat soleus muscle fibres regenerating in the absence of innervation. Development 116:41-53.

Burden SJ, Sargent PB, McMahan UI (1979) Acetylcholine receptors in regenerating muscle accumulate at original synaptic sites in the absence of nerve. J Cell Biol 82:412-425.

Chakravarti S, Tam MF, Chung AE (1990) The basement membrane glycoprotein entactin promotes cell attachment and binds calcium ions. J Biol Chem 265:10597-10603.

Chiu AY, Sanes JR (1984) Development of basal lamina in synaptic and extrasynaptic portions of embryonic rat muscle. Dev Biol 103: 456-467.

Chiu AY, Espinosa de los Monteros E, Cole RA, Loera S, de Vellis J (1991) Laminin and s-laminin are produced and released by astrocytes, Schwann cells, and schwannomas in culture. Glia 4:11-14.

Chiu AY, Ugozolli M, Meiri K, Ko J (1992) Purification and lectinbinding properties of s-laminin, a synaptic isoform of the laminin B1 chain. J Neurochem 59:10-17.

Chung AE, Durkin ME (1990) Entactin: structure and function. Am J Respir Cell Mol Biol 3:275-282.

Chung AE, Dong L-J, Wu C, Durkin ME (1993) Biological functions of entactin. Kidney Int 43:13-19.

Durkin ME, Chakravarti S, Bartos BB, Liu SH, Friedman RL, Chung AE (1988) Amino acid sequence and domain structure of entactin. Homology with epidermal growth factor precursor and low density lipoprotein receptor. J Cell Biol 107:2749-2756.

Dziadek M, Paulsson M, Timpl R (1985) Identification and interaction repertoire of large forms of the basement membrane protein nidogen. EMBO J 4:2513-2518.

Engvall E, Earwicker D, Haaparanta T, Ruoslahti E, Sanes JR (1990) Distribution and isolation of four laminin variants; tissue restricted distribution of heterotrimers assembled from five different subunits. Cell Reg 1:731-740.

Glicksman M, Sanes JR (1983) Differentiation of motor nerve terminals formed in the absence of muscle fibers. J Neurocytol 12:661671. 
Goldman D, Carlson BM, Staple J (1991) Induction of adult-type nicotinic acetylcholine receptor gene expression in noninnervated regenerating muscle. Neuron 4:649-658.

Green TL, Hunter DD, Chan W, Merlie JP, Sanes JR (1992) Synthesis and assembly of the synaptic cleft protein S-laminin by cultured cells. J Biol Chem 267:2014-2022.

Hall ZW (1973) Multiple forms of acetylcholinesterase and their distribution in endplate and non-endplate regions of rat diaphragm muscle. J Neurobiol 4:343-361.

Hall ZW, Kelly RB (1971) Enzymatic detachment of endplate acetylcholinesterase from muscle. Nature New Biol 232:62-64.

Hall ZW, Sanes JR (1993) Synaptic structure and development: the neuromuscular junction. Cell 72/Neuron 10[Suppl]:99-121.

Hawke DH, Harris DC, Shively JE (1985) Microsequence analysis of peptides and proteins. Anal Biochem 147:315-330.

Hunter DD, Sanes JR, Chiu AY (1987) An antigen concentrated in the basal lamina of the neuromuscular junction. Soc Neurosci Abstr 13:375.

Hunter DD, Shah V, Merlie JP, Sanes JR (1989a) A laminin-like adhesive protein concentrated in the synaptic cleft of the neuromuscular junction. Nature 338:229-234.

Hunter DD, Porter BE, Bulock JW, Adams SP, Merlie JP, Sanes JR (1989b) Primary sequence of a motor neuron-selective adhesive site in the synaptic basal lamina protein s-laminin. Cell 59:905-913.

Hunter DD, Cashman N, Morris-Valero R, Bulock JW, Adams SP, Sanes JR (1991) An LRE (leucine-arginine-glutamate)-dependent mechanism for adhesion of neurons to S-laminin. J Neurosci 11: 3960-3971

Jo SA, Burden SJ (1992) Synaptic basal lamina contains a signal for synapse-specific transcription. Development 115:673-680.

Ko C-P (1987) A lectin, peanut agglutinin, as a probe for the extracellular matrix in living neuromuscular junction. J Neurocytol 16: 567-576.

Ko CP (1991) Peanut agglutinin as a probe for studying remodeling and differentiation of synaptic extracellular matrix at the frog neuromuscular junction. In: Plasticity of motoneuronal connections (Wernig A, ed), pp 51-62. New York: Elsevier.

Krejci E, Coussen F, Duval N, Chatel J-M, Legay C, Puype M, Vanderkerckhove J, Cartaud J, Bon S, Massoulié J (1991) Primary structure of a collagenic tail peptide of Torpedo acetylcholinesterase: co-expression with catalytic subunit induces the production of collagen-tailed forms in transfected cells. EMBO J 10:1285-1293.

Laemmli UK (1970) Cleavage of structural proteins during the assembly of the head of bacteriophage T4. Nature 227:680-685.

Mann K, Deutzmann R, Aumailley M, Timpl R, Raimondi L, Yamada Y, Pan T-C, Conway D, Chu M-L (1989) Amino acid sequence of mouse nidogen, a multidomain basement membrane protein with binding activity for laminin, collagen IV and cells. EMBO J 8:65-72.

McMahan UJ, Slater CR (1984) The influence of basal lamina on the accumulation of acetylcholine receptors at synaptic sites in regenerating muscle. J Cell Biol 98:1453-1473.

McMahan UI, Sanes IR, Marshall LM (1978) Cholinesterase is associated with the basal lamina at the neuromuscular junction. Nature 271:172-174.

McMahan UJ, Horton SE, Werle MJ, Honig LS, Kröger S, Ruegg MA, Escher G (1992) Agrin isoforms and their role in synaptogenesis. Curr Opin Cell Biol 4:869-874.

Muir D, Engvall E, Varon S, Manthorpe M (1989) Schwannoma cell- derived inhibitor of the neurite-promoting activity of laminin. J Cell Biol 109:2353-2362.

Nastuk MA, Fallon JR (1993) Agrin and the molecular choreography of synapse formation. Trends Neurosci 16:72-76.

Paulsson M, Aumailley M, Deutzmann R, Timpl R, Beck K, Engel J (1987) Laminin-nidogen complex. Extraction with chelating agents and structural characterization. Eur J Biochem 166:11-19.

Reist NE, Werle MJ, McMahan UJ (1992) Agrin released by motor neurons induces the aggregation of acetylcholine receptors at neuromuscular junctions. Neuron 8:865-868.

Ribera J, Esquerda JE, Comella JX, Poca MA, Bellmunt MJ (1987) Receptors to agglutinin from Dolichus biflorus (DBA) at the synaptic basal lamina of rat neuromuscular junction. A histochemical study during development and denervation. Cell Tissue Res 248:111-117.

Sanes JR (1989) Extracellular matrix molecules that influence neural development. Annu Rev Neurosci 12:491-516.

Sanes JR, Cheney JM (1982) Lectin binding reveals a synapse-specific carbohydrate in skeletal muscle. Nature 300:646-647.

Sanes JR, Chiu AY (1983) The basal lamina of the neuromuscular junction. Cold Spring Harbor Symp Quant Biol 48:667-678.

Sanes JR, Hall ZW (1979) Antibodies that bind specifically to synaptic sites on muscle fiber basal lamina. J Cell Biol 83:357-370.

Sanes JR, Marshall LM, McMahan UJ (1978) Reinnervation of muscle fiber basal lamina after removal of myofibers. Differentiation of regenerating axons at original synaptic sites. J Cell Biol 78:176-198.

Sanes JR, Engvall E, Butkowski R, Hunter DD (1990) Molecular heterogeneity of basal laminae: isoforms of laminin and collagen IV at the neuromuscular junction and elsewhere. J Cell Biol 111:16851699.

Scott LJC, Bacou F, Sanes JR (1988) A synapse-specific carbohydrate at the neuromuscular junction: association with both acetylcholinesterase and a glycolipid. J Neurosci 8:932-944.

Senior RM, Gresham HD, Griffin GL, Brown EJ, Chung AE (1992) Entactin stimulates neutrophil adhesion and chemotaxis through interactions between its arg-gly-asp (RGD) domain and the leukocyte response integrin. J Clin Invest 90:2251-2257.

Tello F (1907) Degeneration et regeneration des plaques motrices apres la section des nerfs. Trav I ab Invest Biol Univ Madrid 5:117-149.

Timpl R, Dziadek M, Fujiwara S, Nowack H, Wick G (1983) Nidogen: a new, self-aggregating basement membrane protein. Eur J Biochem 137:455-465.

Ugozzoli M, Chiu AY (1992) Separation and purification of high molecular weight glycoproteins using agarose gel electrophoresis. Biotechniques 12:187-190.

Wu C, Chung AE (1991) Potential role of entactin in hemostasis. Specific interaction of entactin with fibrinogen A $\alpha$ and $\mathrm{B} \beta$ chains. J Biol Chem 266:18802-18807.

Wu C, Reing J, Chung AE (1991) Entactin forms a complex with fibronectin and co-localizes in the extracellular matrix of the embryonal carcinoma-derived 4CQ cell line. Biochem Biophys Res Commun 178:1219-1225.

Xiao Z-C, Deng L, Ko C-P (1993) Identification of a synaptic extracellular matrix molecule from Torpedo electric organs. Soc Neurosci Abstr 19:700.

Yelian FD, Edgeworth N $\Lambda$, Dong LJ, Chung AE, Armant DR (1993) Recombinant entactin promotes mouse primary trophoblast cell adhesion and migration through the arg-gly-asp (RGD) recognition sequence. J Cell Biol 121:923-929. 